\title{
Theoretical Interpretations of Electronic and Fluorescence Spectra of New 2(1H)-Pyridone Derivatives in Solution and Solid State
}

\author{
Yasuhiro Shigemitsu ${ }^{\text {a,b* }}$, Masayori Hagimoric, Naoko Mizuyamad, Bo-Cheng Wang ${ }^{\mathrm{e}}$, \\ Yoshinori Tominaga ${ }^{\mathrm{d}}$
}

${ }^{a}$ Industrial Technology Center of Nagasaki, 2-1303-8, Ikeda, Omura, Nagasaki 856-0026, Japan

${ }^{b}$ Graduate School of Engineering, Nagasaki University, 1-14, Bunkyo-machi, Nagasaki 852-8131, Japan

${ }^{c}$ Faculty of Pharmaceutical Sciences, Kobe Pharmaceutical University, 4-19-1 Motoyamakita Machi, Higashinada Ku, Kobe 658-8558, Japan

${ }^{d}$ Faculty of Environmental Studies, Nagasaki University, 1-14, Bunkyo-machi, Nagasaki 852-8131, Japan ${ }^{e}$ Department of Chemistry, Tamkang University, Tamsui 251, Taiwan

Correspondence author: Tel:+81-957-52-1133; fax:+81-057-52-1136.

E-mail address: shige@tc.nagasaki.go.jp (Y.Shigemitsu)

A combined experimental and computational study was performed for the spectroscopic properties of novel 2(1H)-pyridones. The compounds were found to be virtually non-fluorescence in solution while modestly fluorescent in solid state. The solvent effects on the UV-vis and fluorescence maxima were estimated by means of a series of ab-initio quantum chemical calculations in conjunction with Polarizable Continuum Model (PCM) method. Influence of structural displacements and intermolecular interactions in crystalline state were examined in details on the spectra of two representative compounds by using Fragment Molecular Orbital (FMO) scheme. The FMO pair interaction analysis of the spectra indicate that (1) intermolecular hydrogen bonds provoke bathochromic shifts (2) electrostatic interactions induce hypsochomic shifts (3) crystal packing effects induce hypsochomic shifts in total from the maxima in vacuo. 
Keywords: 2(1H)-pyridones; quantum chemical calculations; electronic spectra; solid-state fluorescence

\section{Introduction}

Spectroscopic properties of functional dyes have been widely studied and their fluorescence in solid state has attracted much attention owing to organic light-emitting diode (OLED) applications [1-5]. In general, fluorescent compounds show intense luminescence in dilute solution while fairly weak or nonluminescent in the crystalline state [6], due to enhanced non-emissive deactivation channels such as exciton/excimer formation, vibronic interactions and other nonradiative decay processes in aggregated states. Interestingly, many opposite phenomena have been reported today to the conventional emission quenching, where strong luminescence is observed in the solid state whereas negligible luminescence in dilute solution. This anomaly is called Aggregation Induced Emission Enhancement (AIEE) [7-9].

From theoretical viewpoints, a sophisticated treatment of a large condensed phase system is required to understand AIEE and such state-of-the-art methodologies are still being developed. In order to circumvent huge computational costs in direct treatment of a whole system, modern quantum chemistry techniques are based on the idea to divide them into fragments [10-11] or to hybridize several theoretical levels allocated to multiply divided layers such as QM/MM (quantum mechanics/molecular mechanics) [12] or ONIOM (Our Own N-layered Integrated Molecular Orbital ) [13].

Various pyridine derivatives including 2-aminopyridine and 2,2'-bipyridyl have been extensively utilized as chelating reagents to effectively form complexes with various metals [14] $4 H$-pyrone derivatives were reported to serve as potential OLED materials [15]. In the course of our study, the structure-fluorescence relationship were elucidated for 6-aryl-2H-pyran-2-one derivatives bearing push-pull intramolecular charge transfer systems which showed fluorescence both in solution and in the solid phase [16]. The synthesis and fluorescent properties of novel 5-aryl-2,2'-bipyridyls were presented as well as the X-ray structural analysis and the computational studies [17].

Herein, we report and discuss the synthesis, spectroscopic properties and computational studies of new 2(1H)-pyridones, 1-substituted 6-aryl-2(1H)-pyridone and 6-aryl-2-methoxypyridine derivatives. The computational analysis is focused on the condensed phase effects exerting on the spectroscopic properties, by means of ONIOM and FMO methods to evaluate the electronic structures in 
solution as well as in the crystalline phase. From physicochemical viewpoints, 2(1H)-pyridone, the simplest compound, has attracted much attention on its keto-enol tautomerism associated with inter- and intra-molecular hydrogen atom transfer, and been examined in detail on the rotational Duschinsky effect [18], cluster structures in solvents [19], phase transition in solid state [20]. Borst et al. reported that the complex of the two tautomers showed stronger fluorescence than solely respective species [21]. The compounds possess medical properties found in antibacterial antifungal as potential drug candidates for various diseases [22-23].

This article is organized as follows. The synthesis and spectroscopic properties are concisely described and followed by the computational details. The calculation results are presented and discussed on the UV-vis and fluorescence of the compounds both in solution and in the solid state, then brief conclusions are presented.

\section{Syntheses, UV-vis and fluorescence spectra}

A convenient synthesis of poly functionalized-2(1H)-pyridones through the reaction of various methyl ketones with ketene dithioacetals has been reported previously [24]. It has been found that ketene dithioacetals are useful and convenient reagents for the synthesis of a variety of heterocycles [25]. Figure 1 illustrates the synthetic scheme of the present study, whereby the reactions occurred smoothly in the presence of sodium hydroxide in dimethylsulfoxide to give 6-aryl-4-methylsulfanyl-2(1H)-pyridone-3-carbonitril es 3, which were further converted into 6-aryl-4-pyrrolidino-2(1H)-pyridones 2-methoxypyridine 6 and 1-methyl-2(1H)-pyridone 7. One-pot synthesis was attempted instead of the selective methylation [26] to obtain both 6 and 7, which were separated easily upon eluting silica-gel column. 1-Methyl-4-pyrrolidono-2(1H)-pyridones 8 were obtained from 7 via the reactions with pyrrolidine, as illustrated in Fig.1, 2 and 3.

The measurement of absorption and fluorescence spectra was carried out at room temperature in ethanol and in the solid state, respectively. Absorption maxima, molar absorption, fluorescence maxima, and relative fluorescence intensities in the solid state are listed in Tables 1, 2 and 3. In ethanol, 3f, some 2-methoxypyridines $\mathbf{6}$ and $\mathbf{7 f}$ were found to be slightly fluorescent with their quantum yields less than 0.03 . Remaining 2(1H)-pyridones $\quad 3 \quad$ and 1-methyl-2(1H)-pyridones 7 were non-fluorescent. In general, sulfur atoms in fluorescent compounds generally weaken emission intensities due to spin orbit couplings [17][27]. In the solid state, the fluorescence properties of 2(1H)-pyridone are expected to be influenced by both the electronic and the steric effect of substituents, as shown in a previous 
study of 2(1H)-pyrones [16]. Compound $\mathbf{3 b}$ with an electron-donating group at position 4 on the phenyl ring showed enhanced emission with Relative Intensity (R.I.) of 1.28, significantly larger than that of 3a (0.99). The fluorescent intensity of 6-(3,4-dimethoxyphenyl)-2(1H)-pyridone $\quad$ 3c and 3,4,5-trimethoxy-2(1H)-pyridone $\quad 3 \mathbf{e}$ remain unchanged qualitatively. 6-styryl-2(1H)-pyridone $\mathbf{3 k}$ and 6-(4-dimethylaminophenyl)vinyl-2(1H)-pyridone 3I showed their emission maxima at $560 \mathrm{~nm}$ and 564 $\mathrm{nm}$, respectively, with a significant bathochromic shift from other 3 series, owing to an analogous chromophore with 4-(dicyanomethylene)-2-methyl-6-(p-dimethylaminost yryl)-4H-pyran (DCM). 2-methoxypyridines 6 and the corresponding 1-Methyl-2(1H)-pyridones 7, derived from the respective 2-pyridine proton tautomers, have almost the same fluorescence characteristics, in that the introduction of a methoxy group to the phenyl ring (7b) enhances the fluorescence in comparison with 7a and a significant bathochromic shift was observed via the introduction of styryl group $\mathbf{7 k}$.

The details of synthesis and spectroscopic measurements are described in Experimental section.

\section{Computational details}

Ground state geometry optimizations of the single molecules at DFT level were carried out using
B3LYP[28][29] functional with 6-311G(2d,2p) and $\mathrm{S}_{1}$ state geometries were optimized using TDDFT(B3LYP)/6-31+G(d), respectively, with the default convergence criterion on force and displacement. The optimized geometries were validated with vibrational frequency analysis for the compounds. Our TDDFT study has proved that TDDFT(B3LYP)/6-31+G(d) serves as well-balanced level of theory between computational burden and accuracy in the prediction of the absorption $\lambda_{\max }$ of maleimide-derived heterocycles [30]. The single point TDDFT calculations employed PBE0 [31] and CAM-B3LYP[32] functional as well as B3LYP to obtain the vertical $\mathrm{S}_{0}-\mathrm{S}_{1}$ excitation energies and their associated oscillator strengths. Solvent effects of ethanol were considered using two PCM methods, non-equilibrium linear response formulation (LR-PCM) [33] and its state-specific variant (SS-PCM) [34]. Complete Active Space Self Consistent Field CASSCF(10e,10o)/ANO-L and Multi-State second order perturbation to CAS MS-CASPT2(10e,10o)/ANO-L calculations were carried out to quantitatively evaluate the $\lambda_{\max }$.

For the crystalline phase of $\mathbf{7 a}$ and $\mathbf{8 a}$ in the $\mathrm{S}_{0}$ state, ONIOM and FMO-TDDFT [35] calculations were employed to estimate the absorption $\lambda_{\max }$ under the packing influence. The cluster models were extracted from the crystallographic data shown in the Table S-1, 
containing 32 molecules for $\mathbf{7 a}$ and 30 molecules for $\mathbf{8 a}$, respectively within $10 \AA$ apart from the center of mass of the central molecule, as presented in the Figure 2. The X-ray crystallographic analysis for $\mathbf{8 a}$ provided the uncertainty for the pyrrolindino ring position (two structures with equally partial occupancies), therefore the equally averaged geometrical data was adopted. ONIOM(TDDFT:PM3) (TDDFT for the sole central molecule:PM3 for the surrounding lattice molecules) and FMO-TDDFT calculations were applied to the cluster models. FMO-TDDFT calculations employed 6-31G(d) throughout the present study since the more extended basis set larger than $6-31+G(d)$ suffered from FMO convergence failure. The intermolecular interactions were estimated within FMO-TDDFT at the two FMO levels; FMO-1 (including only monomer interactions) and FMO-2 (including up to dimer interactions). A correction to Basis Set Superposition Error (BSSE) was not considered for the present calculations. For the $\mathrm{S}_{1}$ state, cluster models were created through manipulation of the $\mathrm{S}_{0}$ cluster models, in which the geometries were partially optimized by TDDFT(B3LYP)/6-31+G(d) only for the central one molecule with the surrounding lattice molecules fixed in $\mathrm{S}_{0}$ state geometry treated by PM3 level, i.e., two-layer ONIOM (TD(B3LYP)/6-31+G(d): PM3). The model has been already studied as a `frozen-molecule approximation` [36]. The partial geometry optimization with the surrounding PM3 regions fixed has been rationalized by Shuai et al using QM/MM model for 3-cyano-2-phenyl-Z-NH-indole cluster models [37]. Single point FMO-TDDFT calculations were carried out for the ONIOM-optimized geometry to estimate the emission $\lambda_{\max }$.

The DFT, TDDFT and ONIOM calculations were performed by means of Gaussian09 [38], FMO-TDDFT calculations by GAMESS [39], CASSCF and MS-CASPT2 calculations by MOLCAS [40], respectively.

\section{Results and discussion}

4.1 Absorption spectra of $\mathbf{3 , 5 , 6}$ : TDDFT assessment

To verify the applicability of TDDFT, the first intense absorption maxima of compounds 3, 5, 6 series were computed and the results were shown in Table 4. The $\mathrm{S}_{0}-\mathrm{S}_{1}$ vertical excitations are overwhelmingly described by HOMO-LUMO excitations for all the compounds. The computed $\lambda_{\max }$ show fair coincidence with the experiments in ethanol with around $30 \mathrm{~nm}$ deviations, excluding 3k which is not sufficiently soluble. In comparison of $\mathbf{3}$ with $\mathbf{5}$, the hypsochromic shifts invoked by the introduction of pyrroloindolino group were well reproduced at the present TDDFT level. 
4.2 Absorption spectra of $\mathbf{7 a}$ and $\mathbf{8 a}$ both in ethanol and in crystalline phase: ONIOM and FMO-TDDFT calculations

Tables 5 and 6 shows the evolution of absorption $\lambda_{\max }$ of $7 \mathbf{a}$ and $\mathbf{8 a}$ at the series of computational levels.

In vacuo, $\lambda_{\max }$ of $\mathbf{7 a}$ and $\mathbf{8 a}$ show fairly quantitative agreements with experiments at both TDDFT and MS-CASPT2 levels, using the geometries extracted from crystalline state. CASSCF gave substantial $\lambda_{\max }$ over-evaluation owing to the lack of dynamic electron correlation. MS-CASPT2 adequately corrected the CASSCF results toward right prediction. TDDFT using B3LYP functional showed that $6-31+G(d, p)$ have a qualitative accuracy with its deviation from that of 6-311G++(3df,2dp) only $4 \mathrm{~nm}$ for 7a. That means the compact $6-31+G(d, p)$ basis set can ensure the quantitative accuracies in the present study. The computed $\lambda_{\max }$ showed a hypsochromic shift in the order of B3LYP $<$ PBE0 $<$ CAM-B3LYP; the trend agrees with the XC-functional performances generally established [41].

In ethanol, the two PCM schemes, LR-PCM and SS-PCM, were tested to estimate the solvent effect on the $\lambda_{\max }$. For $\mathbf{7 a}$, LR-PCM invoked an apparent blue-shift by $10 \mathrm{~nm}$ while SS-PCM give virtually no shift (1 nm), using TD(B3LYP)/6-31+G(d). The same trend was observed for $\mathbf{8 a}$. The results point out that
SS-PCM, which can treat the excited state more flexibly adapted to the excited state than LR-PCM and assumes more accurate results, elucidated the minor role of ethanol exerted on the $\lambda_{\max }$ at PCM level. The PCM solvent effect on MS-CASPT2 works hypsochromically by up to $32 \mathrm{~nm}$. The best agreement with experiments among the solvent-considered calculations were obtained by SS-PCM-TD(B3LYP)/6-31+G(d,p) for $7 \mathbf{a}$ (12 nm deviation) and by vac-MS-CASPT2(10e,10o)/ANO-L for $\mathbf{8 a}$ (1 nm deviation), respectively.

In the crystalline states, head-to-tail pairs are stacked for both $\mathbf{7 a}$ and $\mathbf{8 a}$ (dimer-1) with an interplanar distance over $4 \AA$, which imply that strong $\pi-\pi$ interactions are not invoked but modest dipole-dipole interactions induced instead in the stacking direction as illustrated in Figure 3 and 4 . On the other hand, the shortest O-H distance between the parallel adjacent molecules is $2.59 \AA$ (7a) and $2.39 \AA$ (8a) (dimer-2), respectively, which means substantial hydrogen bond interactions were invoked. The hydrogen pairing caused bathochromic shifts of $40 \mathrm{~nm}(\mathbf{7 a})$ and $14 \mathrm{~nm}(\mathbf{8 a})$ at the TD(B3LYP)/6-31G(d) level. The HOMO-1,HOMO, LUMO and LUMO+1 of $7 \mathbf{a}$ dimer-2 are localized on each monomers, as shown in Figure 5. The $\mathrm{S}_{0}-\mathrm{S}_{1}$ oscillator strength of the dimer-2 was larger (0.336: 7a) than monomer (0.204: 7a) because the pairwise local excitations (HOMO-1 to LUMO, HOMO to LUMO+1) 
are almost equally superimposed and enhanced in the dimer- $2 \mathrm{~S}_{1}$ state. The calculated dipole moments of the monomers were directed from the central pyridine ring toward the phenyl ring, with the strength of 14.4 (7a) and 13.2 (8a) debye, respectively.

The two layer ONIOM(TDDFT:PM3) results gave negligible shifts to $\lambda_{\max }$, which implys the electrostatic interactions across the two layers may not be properly treated at semiempirical MO levels. In comparison with the hypsochromic shift obtained by FMO1-TDDFT which include only one-body interactions, point charge approximation to the surrounding PM3 shells (Mulliken charges on the surrounding molecules treated by PM3 are nullified) did not properly describe the coulombic interactions between DFT and PM3 regions. ONIOM-optimized geometrical distortions are compared with X-ray crystallographic data in Table 7, which illustrate the inter-ring C-C bond lengths and the relevant torsion angles in good agreement within ca. $0.01 \AA$ and 1.5 degree deviations for 7a, respectively. 8a shows modest deviation of the twist angles with ca. 6 degrees between the ONIOM-optimized and X-ray angles, which imply that 8a in the solid state is influenced by crystal field which make it favorable to stay in more planar conformation.

The importance of appropriate treatment of surrounding molecules in solid state is indicated by the FMO-TDDFT results for the same cluster models, as presented in Table 8. The FMO1-TDDFT invoked the blue shift by 11 for 7a and $23 \mathrm{~nm}$ for $\mathbf{8 a}$, respectively, in comparison with the in-vacuo results. FMO2-TDDFT, which consider up to pairwise 2-body interactions with the central monomer, invoked inverse adjustment by 5 $\mathrm{nm}$ from FMO1-TDDFT to predict $\lambda_{\max }$ at $326 \mathrm{~nm}$. The bathochromic shift in FMO2-TDDFT was presumably derived from the same behavior between monomer and dimer with a $9 \mathrm{~nm}$ red shift. Provided that the $6 \mathrm{~nm}$ gap between TD(B3LYP)/6-31G(d) and TD(B3LYP)/ 6-311++G(3df,2dp) can be extrapolated to the case of FMO2-TDDFT, the most sophisticated strategy in the $\begin{array}{lll}\text { present } & \text { TDDFT } & \text { study }\end{array}$ FMO2-TDDFT/6-311++G(3df,2dp) would give 332 nm with only $2 \mathrm{~nm}$ deviation form the experiment $334 \mathrm{~nm}$, in excellent agreement for 7a. Still, the small blue shift was experimentally observed for $\mathbf{7 a}$ in solid (334 nm) in comparison with in ethanol (350 nm) while the substantial red shift was noted for $\mathbf{8 a}$ between in solid (394 nm) and in ethanol (310 nm). The inconsistency for 8a with substantial gap between theory and experiment is not satisfactorily explainable at the present computational levels.

The individual contributions from the FMO2 pairs to $\lambda_{\max }$ were examined in detail, as shown in Table S-2. For 7a, the largest contribution to excitation energy is derived from the pair interaction with the $14^{\text {th }}$ molecule giving a $0.040 \mathrm{eV}$ hypsochromic shift, followed by the 
next largest contribution from $12^{\text {th }}$ molecule with -0.033 $\mathrm{eV}$, followed by $11^{\text {th }}$ with $-0.018 \mathrm{eV}$. The $14^{\text {th }}$ molecule is aligned with $1^{\text {st }}$ in an anti-parallel fashion while $12^{\text {th }}$ and $11^{\text {th }}$ is interconnected with $1^{\text {st }}$ via a hydrogen bond. The bathochromic shift induced by an intermolecular hydrogen bond has been already reported by a FMO-TDDFT study of quinacridone crystals [42]. The resulting excitation energy of $\mathbf{7 a}$ was calculated to be $326 \mathrm{~nm}$, with $6 \mathrm{~nm}$ bathochromic shift from $320 \mathrm{~nm}$ at FMO1 level. The modest contributions from the pair interactions with $6 \mathrm{~nm}$ red shift were observed for $\mathbf{8 a}$ as well.

\subsection{Emission spectra of $\mathbf{3 f}$}

Table 9 illustrates the solvent effect on the first intense emission $\lambda_{\max }$ computationally assessed for $\mathbf{3 f}$, which exhibited highest fluorescence quantum yield 0.03 among the present molecules in ethanol. LR-PCM calculations provided small $\lambda_{\max }$ shifts within $10 \mathrm{~nm}$ irrespective of the XC-functionals employed, while SS-PCM gave substantial bathochromic shifts by over $30 \mathrm{~nm}$. SS-PCM-TD(B3LYP)/6-31+G(d) gave the best coincidence with the experiment with $38 \mathrm{~nm}$ deviation. The result of MS-CASPT2 worsened the coincidence even including the solvent effect, where PCM solvent effect might excessively destabilize the $\mathrm{S}_{1}$ state, leading to the widened $\mathrm{S}_{1}-\mathrm{S}_{0}$ vertical gap. This irregularity of
PCM could indicate the limitation of the present PCM implementation combined with MS-CASPT2.

A substantially bathochromic shift invoked by the packing effect was observed in the solid state compared to that in ethanol by $50 \mathrm{~nm}$ (Table 1). Unfortunately we failed to obtain the crystals so we could not computationally estimate the emission $\lambda_{\max }$ using the crystalline structure. The packing effects on emission $\lambda_{\max }$ are discussed in the following subsection 4.4 for 7a and 8a of which crystal structures are available.

4.4 Emission spectra of 7a and 8a both in ethanol and in solid state: ONIOM and FMO-TDDFT calculations

As shown in Table 7, the key C4-C7 bond length of 7a becomes shortened by $0.04 \AA$ in comparison with the optimized geometries in vacuo in the $\mathrm{S}_{0}$ and the $\mathrm{S}_{1}$ states. The associated inter-ring twisting angle between the central pyridine ring and the phenyl counterpart was restored by 25 degrees in the $S_{1}$ state. This indicates that the electronic resonance between the $\mathrm{C} 4-\mathrm{C} 7$ bond is somewhat restored in the $\mathrm{S}_{1}$ state. Such resonance restoration was computed for $\mathbf{8 a}$ as well. The geometrical distortions between in vacuo-optimized and ONIOM-optimized structures are quite small in the $S_{1}$ state as in the $\mathrm{S}_{0}$ state. The ONIOM-optimized structures, interestingly, showed that the skeletal twisting angles become larger by 14 degrees both for $\mathbf{7 a}$ 
and 8a. It is unclear whether the enhanced distortion is caused by the surrounding lattice molecules or simply the irregularity of the finite cluster model.

Table 10 shows the computed emission $\lambda_{\max }$ evolution. In vacuo, the emission $\lambda_{\max }$ dependency on the basis set shows the trend similar to those of the UV-vis $\lambda_{\max }$, namely, the bathochromic shift for the two molecules. The best coincidence was obtained using B3LYP among the three XC-fuctionals with the experimental emission $\lambda_{\max }$ in the solid state. As in the case of the $\mathrm{S}_{0}$ state, CASSCF $\lambda_{\max }$ was adequately corrected by MS-CASPT2, giving $418 \mathrm{~nm}$ with $30 \mathrm{~nm}$ deviation from TD(B3LYP)/6-31+G(d) for 7a. The calculated dipole moment vector in the $S_{1}$ state possess the strength of 11.8 (7a) and 10.6 (8a) debye respectively, directing from the central pyridine ring toward phenyl ring, as in the $\mathrm{S}_{0}$ state.

The ONIOM emission $\lambda_{\max }$ were predicted at 421 (435) nm for 7a (8a) at TD(B3LYP)/6-31G(d) level, 25 (28) nm blue shift than the TDDFT results in vacuo, respectively. Considering the negligible ONIOM effect on the $\mathrm{S}_{0}$ state where quite small absorption $\lambda_{\max }$ shifts were invoked, the substantial emission red shifts were caused by the considerable geometrical distortions in the $\mathrm{S}_{1}$ state which exerted on the emission center molecule embedded in the surrounding molecules as a result of the geometry optimizations.

As shown in Table 8, FMO-TDDFT $\lambda_{\max }$ on the
ONIOM-geometries exhibited further hypsochromic shift from the ONIOM-TDDFT results; for 7a $403 \mathrm{~nm}$ by FMO-1 and 415 nm by FMO-2, and for 8a 392 nm by FMO-1 and 397 nm by FMO-2, respectively. The dimer interactions between the emission center and the surrounding molecules considered in FMO-2 adjusted the $\lambda_{\max }$ toward bathochromic directions, as in the case in the $\mathrm{S}_{0}$ state. The $\lambda_{\max }$ coincidence between the experiments and calculations are much worse than the case of the $\mathrm{S}_{0}$ state in which almost perfect coincidence was obtained at FMO2-TDDFT level. The substantial $\lambda_{\max }$ gap of 51 (87) $\mathrm{nm}$ for $7 \mathbf{a}(\mathbf{8 a})$ remains even at the FMO2-TDDFT level, respectively. Considering the good coincidence of MS-CASPT2 and FMO2-TDDFT, the substantial gap might be attributed not only to the computational accuracies, but to the large displacement between FC- $S_{1}$ and the $S_{1}$ minima; the emissive $S_{1}$ state is supposedly located not at the FC-S ${ }_{1}$ point or nearby but at the point far from FC-S 1 as result of geometrical relaxations. The precise $S_{1}$ energy surface exploration, however, goes beyond the present study.

The FMO2-TDDFT individual pair contributions to $\lambda_{\max }$ shift are shown in Table S-2. For $\mathbf{7 a}$, the largest contribution to the FMO-1 $\lambda_{\max }(403 \mathrm{~nm})$ come from the interaction with the $11^{\text {th }}$ molecule of $-0.027 \mathrm{eV}$ hypsochromic shift, followed by the next largest contribution with the molecule $10^{\text {th }}$ of $-0.023 \mathrm{eV}$ followed by $6^{\text {th }}$ of $0.015 \mathrm{eV}$, leading to the resulting 
FMO-2 $\lambda_{\max }$ calculated to be $415 \mathrm{~nm}$ of $12 \mathrm{~nm}$ bathochromic shift. The two blue-shift-causing pairs were interconnected with the center molecule through hydrogen bonds while the red-shift-causing pair was stacked in an anti-parallel fashion, as show in Figure 6. The modest contributions from the pair interactions with $5 \mathrm{~nm}$ red shift was observed for $\mathbf{8 a}$ as well by introduction of the two-body interaction corrections into FMO-1, as shown in Table 8.

The present study ignored electrostatic interactions from infinite distances in the crystalline state; the crystal field effect can contribute at the same magnitude as structure deformation and intermolecular interactions to excitation energy [42]. The cluster size dependency, new XC-functionals to treat dispersion interactions, higher order correction beyond two-body interactions in FMO-TDDFT, the adequacy of the 'frozen-molecule approximation'[36] will be studied in due course.

\section{Conclusion}

In summary, a joint experimental and computational study of UV-vis and fluorescence first intense maxima of the new 2(1H)-pyridone derivatives was presented and discussed in vacuo, in solution and in the solid state. The UV-vis peaks of the compounds appeared between $310-449 \mathrm{~nm}$ in ethanol. Some of them showed modest fluorescence in solid state in the range of $431-564 \mathrm{~nm}$ but quite weak or no fluorescence in solution. The
TDDFT and MS-CASPT2 calculations including solvent effects reveal that the two PCM methodologies, LR-PCM and SS-PCM, affect the UV-vis and emission peak shifts in a quantitatively different way. The UV-vis and fluorescence peaks of the two representative compounds (7a, 8a) in the solid state were examined in detail by means of ONIOM and FMO-TDDFT methods, in order to analyze an interplay between geometrical distortions and intermolecular interactions. For the absorption $\lambda \max$, intermolecular hydrogen bonds considered by FMO2 invoked red shifts whereas non-hydrogen bond interactions induced blue shift, giving bathochromic shift in total from FMO1. The overall packing effects treated by FMO2-TDDFT invoked blue shift of $11 \mathrm{~nm}$ from $\lambda_{\max }$ of $7 \mathbf{a}$ in vacuo, also $23 \mathrm{~nm}$ blue shift from that of $\mathbf{8 a}$. The ONIOM influence on the absorption $\lambda_{\max }$ derived from the surrounding molecules is quite marginal within $1 \mathrm{~nm}$ shift. The minor influence of ONIOM on the absorption $\lambda_{\max }$ indicates that the substantial ONIOM influence on the emission $\lambda_{\max }$ comes from the geometrical deviations in the $S_{1}$ state by the surrounding molecules, not from the direct perturbation to the electronic structure of the emissive molecule.

\section{Acknowledgement}

One of the authors (Y.S.) thanks to Dr. Takeshi 
Ishikawa of Nagasaki University for his helpful discussions on the interpretations of ONIOM and FMO-TDDFT calculations. This study was financially supported in part by Grants-in-Aid for Scientific Research (C) (No. 24550058, Y.S.) from Japan Society for the Promotion of Science.

\section{References}

[1] Shirai K, Matsuoka M, Fukunishi K. New syntheses and solid state fluorescence of azomethine dyes derived from diaminomaleonitrile and 2,5-diamino-3,6-dicyanopyrazine. Dyes and Pigments 2000; 47: 107-115. and references therein

[2] He Z, Kan C.W., Ho C.L., Wong W.Y., Chui C.H., Tong K.L., So S.K., Lee T.H., Leung L.M., Lin Z. Light-emitting dyes derived from bifunctional chromophores of diarylamine and oxadiazole: Synthesis, crystal structure, photophysics and electroluminescence, Dyes and Pigments, 2011; 88:333-343.

[3] Tang K-C., Chang M-J, Lin T-Y, Pan H-A., Fang T-C, Chen K-Y, Hung W-Y, Hsu Y-H, Chou T-P., Fine Tuning the Energetics of Excited-State Intramolecular Proton Transfer (ESIPT): White Light Generation in A Single ESIPT System. J. Am. Chem. Soc. 2011; $133,: 17738-17745$

[4] Zhang Q, Li J, Shizu K, Huang S, Hirata S, Miyazaki H, Adachi C, Design of Efficient Thermally
Activated Delayed Fluorescence Materials for Pure Blue Organic Light Emitting Diodes. J. Am. Chem. Soc. 2012;134:14706-14709

[5] Li J., Duan Y, Li Q. Novel thieno-[3,4-b]-pyrazine derivatives for non-doped red organic light-emitting diodes. Dyes and Pigments, 2013; 96: 391-396.

[6] Park S-Y, Ebihara M, Kuroda Y, Funabiki K, Matsui M. The relationship between solid-state fluorescence intensity and molecular packing of coumarin dyes. Dyes and Pigments 2009; 82: 258-267.

[7] An B-K, Kwon S-K, Jung, S-D, Park S-Y. Enhanced emission and its switching in fluorescent organic nanoparticles. J. Am. Chem. Soc. 2002; 124: 14410-14415.

[8] Feng X, Tong B, Shen J, Shi J, Han T, Chen L, Zhi J, Lu P, Ma Y, Dong Y. Aggregation-Induced Emission Enhancement of Aryl-Substituted Pyrrole Derivatives. J. Phys. Chem. B 2010;114:16731-16736. [9] Xie Y-Z, Shan G-G, Li P, Zhou Z-Y, Su Z-M. A novel class of $\mathrm{Zn}$ (II) Schiff base complexes with aggregation-induced emission enhancement (AIEE) properties: Synthesis, characterization and photophysical/electrochemical properties. Dyes and Pigments, 2013;96:467-474.

[10] Kitaura K, Ikeo E, Asada T, Nakano T, Uebayasi M. Fragment molecular orbital method: an approximate computational method for large molecules. Chem. Phys. Lett. 1999; 313:701-706. 
[11] Kitaura K, Fedrov D.G. Eds. The Fragment Molecular Orbital Method, CRC press, New York, 2009.

[12] Canuto S, Sabin J.R. Eds, Combining Quantum Mechanics and Molecular Mechanics. Some Recent Progresses in $\mathrm{QM} / \mathrm{MM}$ Methods, in Advances in Quantum Chemistry Volume 59, 2011,Academic press, and references therein

[13] Dapprich S, Komáromi I, Byun KS, Morokuma K, Frisch M.J, A New ONIOM Implementation in Gaussian 98. 1. The Calculation of Energies, Gradients and Vibrational Frequencies and Electric Field Derivatives. J. Mol. Struct. (Theochem). 1999; 462:1-21.

[14] Kaes C, Katz A, Hosseini MW. Bipyridine: The Most Widely Used Ligand. A Review of Molecules Comprising at Least Two 2,2`-Bipyridine Units. Chem. Rev. 2000;100:3553-3590. and references therein

[15] Chen CH, Tang CW, Shi J, Klubeck .P, Recent developments in the synthesis of red dopants for $\mathrm{Alq}_{3}$ hosted electroluminescence. Thin Solid Films 2000;363:327-331. and references therein

[16] Mizuyama N, Murakami Y, Kohra S, Ueda K, Hiraoka K, Nagaoka J, Takahashi K, Shigemitsu Y, Tominaga Y. Synthesis and Fluorescence of 2H-Pyrone Derivatives for Organic Light-emitting Diodes (OLED) . Journal of Heterocyclic Chemistry 2007;44,:115-132.

[17] Mizuyama N, Tominaga Y, Kohra S, Ueda K,
Hirayama S, Shigemitsu Y. Synthesis and Steady-State Spectroscopic Study of 5-Aryl-2,2'-bipyridyls. New Fluorescent Compounds in Solid State. Bull. Chem. Soc. Jpn, 2006;79, 602-611.

[18] Held A, Champagne BB, Pratt DW. Inertial axis reorientation in the $S_{1}<-S_{0}$ electronic transition of 2-pyridone. A rotational Duschinsky effect. Structural and dynamical consequences. J.Chem.Phys. 1991;5:8732-8743.

[19] Matsuda Y, Ebata T, Mikami N. Vibrational spectroscopy of 2-pyridone and its clusters in supersonic jets : Structures of the clusters as revealed by characteristic shifts of the $\mathrm{NH}$ and $\mathrm{C}=0$ bands. J.Chem.Phys., 1999; 110:8397-8407.

[20] Flakus HT, Tyl A, Maslankiewicz A. Electron-Induced Phase Transition in Hydrogen-Bonded Solid-State 2-Pyridone. J.Phys.Chem.A, 2011;115:1027-1038.

[21] Borst DR, Roscioli JR, Pratt DW, Florio GM, Zwier TS, Muller A, Leutwyler S. Hydrogen bonding and tunneling in the 2-pyridone-2-hydroxypyridine dimer. Effect of electronic excitation. Chem. Phys.2002; 283:341-354.

[22] Casinovi CG, Grandolini G, Mercantini R, Oddo N, Olivieri R, Tonolo A. A new antibiotic produced by a strain of Aspergillus flavipes. Tetrahedron Lett. $1968 ; 3175-3178$.

[23] Datta A, Ila H, Junjappa H. Reformatsky reaction on $\alpha$-oxoketene dithioacetals; Synthesis of substituted 
and fused ethyl-2-hydroxy-6-methylthiobenzoates, 6-methylthio-3(1H)pyridones

6-methyl-thiopyran-2-one derivatives. J. Org. Chem. 1990;55:5589-5594.

[24] Tominaga Y, Kawabe M, Hosomi A. Synthesis of 4-methylthio-2(1H)-pyridone derivatives using ketene dithioacetals. J. Heterocycl. Chem. 1987;24:1327-1331. and references therein

[25] Tominaga Y, Ushirogouchi A, Matsuda Y, Synthesis and reaction of 6-substituted 3-methoxycarbonyl-4-methylthio-2H-pyran-2-one derivatives. J. Heterocycl. Chem., 1987;24:1557-1567. and references therein

[26] Dieter RK. $\alpha$-Oxo ketene dithioacetals and related compounds: versatile three-carbon synthons. Tetrahedron, 1986;42:3029-3096.

[27] Patsenker LD, Artyukhova YY. Molecular structure and spectral properties of thionaphthalimides.

J. Mol. Struct., 2003;655:311-320.

[28] Becke, A. Density - functional thermochemistry.

III. The role of exact exchange. J.Chem.Phys., 1993;98:5648-5652

[29] Lee C, Yang W, Parr RG. Development of the Colle-Salvetti Correlation-Energy Formula into a Functional of the Electron DensityPhys.Rev. B 1998;37:785-789.

[30] Shigemitsu Y, Komiya K, Mizuyama N, Tominaga Y. TD-DFT investigation on the electronic spectra of novel $\mathrm{N}$-methylmaleimides linked with indolizine ring system. J. Mol.Struct. (THEOCHEM), 2008; 855:92-101.

[31] Adamo C, Barone V. Toward reliable density functional methods without adjustable parameters: The PBE0 model. J. Chem. Phys. 1999;110 :6158-69. [32] Yanai T, Tew D, Handy N. A new hybrid exchange-correlation functional using the Coulomb-attenuating method (CAM-B3LYP). Chem. Phys. Lett. 2004;393: 51-57.

[33] Cossi M, Barone V. Time-dependent density functional theory for molecules in liquid solutions. J.Chem.Phys. 2001; 115:4708-4718.

[34] Improta R, Barone V, Scalmani G, Frisch MJ. A state-specific polarizable continuum model time dependent density functional method for excited state calculations in solution. J. Chem. Phys., 2006; 125: $1-9$.

[35] Chiba M, Fedorov DG, Kitaura K. Time-dependent density functional theory with the multilayer fragment molecular orbital method. Chem. Phys. Lett. 2007; 444:346-350.

[36] Li M-C, Hayashi M, Lin S-H. Quantum Chemistry Study on Internal Conversion of Diphenyldibenzofulvene in Solid Phase. J.Phys.Chem.A, 2011; 115:14531-14538.

[37] Wu Q, Peng Q, Niu Y, Gao X, Shuai Z. Theoretical insights into the aggregation-induced emission by hydrogen bonding: a QM/MM study. J 
Phys Chem A 2012; 116:3881-3888.

[38] Gaussian 09 , Rev. A.2, M. J. Frisch, G. W. Trucks, H. B. Schlegel, G. E. Scuseria, M. A. Robb, J.

R. Cheeseman, V. G. Zakrzewski, J. A. Montgomery, Jr., R. E. Stratmann, J. C. Burant, S. Dapprich, J. M. Millam, A. D. Daniels, K. N. Kudin, M. C. Strain, O. Farkas, J. Tomasi, V. Barone, M. Cossi, R. Cammi, B. Mennucci, C. Pomelli, C. Adamo, S. Clifford, J. Ochterski, G. A. Petersson, P. Y. Ayala, Q. Cui, K. Morokuma, D. K. Malick, A. D. Rabuck, K. Raghavachari, J. B. Foresman, J. Cioslowski, J. V. Ortiz, A. G. Baboul, B. B. Stefanov, G. Liu, A. Liashenko, P. Piskorz, I. Komaromi, R. Gomperts, R. L. Martin, D. J. Fox, T. Keith, M. A. Al-Laham, C. Y. Peng, A. Nanayakkara, C. Gonzalez, M. Challacombe, P. M. W. Gill, B. G. Johnson, W. Chen, M. W. Wong, J. L. Andres, M. Head-Gordon, E. S. Replogle and J. A. Pople, Gaussian, Inc., Pittsburgh PA.

[39] GAMESS-US version 2009, Department of Chemistry, Iowa State University, Ames, IA 50011, 2009.

[40] MOLCAS ver.7.4, Lund University, 2008; Aquilante, F.; Vico, L.De.; Ferré, N.; Ghigo, G.; Målmqvist, P.-Å; Neogrády, P.; Pedersen, T.B.; Pitonak, M.; Reiher, M.; Roos, B.O.; Serrano-Andrés, L.; Urban, M.; Veryazov, V.; Lindh, R.

[41] Jacquemin D, Mennucci B, Adamo C. Excited-state calculations with TD-DFT: from benchmarks to simulations in complex environments.
Phys. Chem. Chem. Phys., 2011;13,:16987-16998.

[42] Fukunaga H, Fedrov DG, Chiba M, Nii K, Kitaura K. Theoretical Analysis of the Intermolecular Interaction Effects on the Excitation Energy of Organic Pigments:Solid State Quinacridone. J.Phys.Chem.A, 2008;112:10887-10894. 
Figure Captions

Fig.1. Synthetic scheme of $(3,5,6,7,8)$

Fig.2. ONIOM(DFT:PM3) cluster models of 7a with

32 (upper) and of 8a with 30 molecules (lower). A

DFT-treated center molecule surrounded by

PM3-treated outer molecules.

Fig.3. 7a monomer (top: an allow indicating a dipole direction), dimer-1 (middle left), dimer-2 (middle right), packing form along a-axis (bottom left), along b-axis (bottom right)

Fig.4. 8a monomer (top: an allow indicating a dipole direction), dimer-1 (middle left), dimer-2 (middle right), packing form along a-axis (bottom left), along b-axis (bottom right)

Fig.5. Near-frontier orbitals of 7a dimer-2. HOMO-1 (upper left), HOMO (upper right), LUMO (lower left), LUMO+1 (lower right).

Fig.6. Representative interacting molecules in 7a cluster model in S0 state. A center molecule (red), 14-th (yellowgreen), 11-th (yellow), 12-th (purple).

Fig.7. Representative interacting molecules in 7a cluster model in S1 state. A center molecule (red), 6-th (yellowgreen), 10-th (yellow), 11-th (purple). 
Fig. 1.

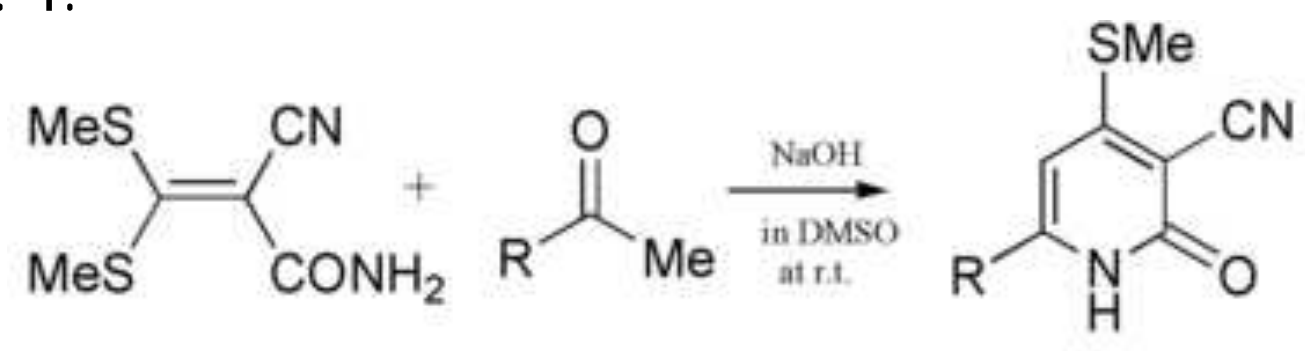

1a

2a-1

3a-I<smiles>[R]c1cc([N+](=O)[O-])c(C#N)c(=O)[nH]1</smiles>

3a, b, c, d, e

$4 a, b, c, d, e$

$5 \mathrm{a}, \mathrm{b}, \mathrm{c}, \mathrm{d}, \mathrm{e}$

in

3a-I<smiles>[R]c1cc(S(C)(=O)=O)c(C#N)c(OC)n1</smiles>

6a-1<smiles>[R]c1cc(S(C)(=O)=O)c(C#N)c(=O)n1C</smiles>

7a-k<smiles>[R]c1cc(S(C)(=O)=O)c(C#N)c(=O)n1C</smiles>

$7 a-e$<smiles>[R]c1cc(C)c(C#N)c(=O)n1C</smiles>

8a-e

Fig. 1. Synthetic scheme of $(3,5,6,7,8)$ 
Fig. 2.

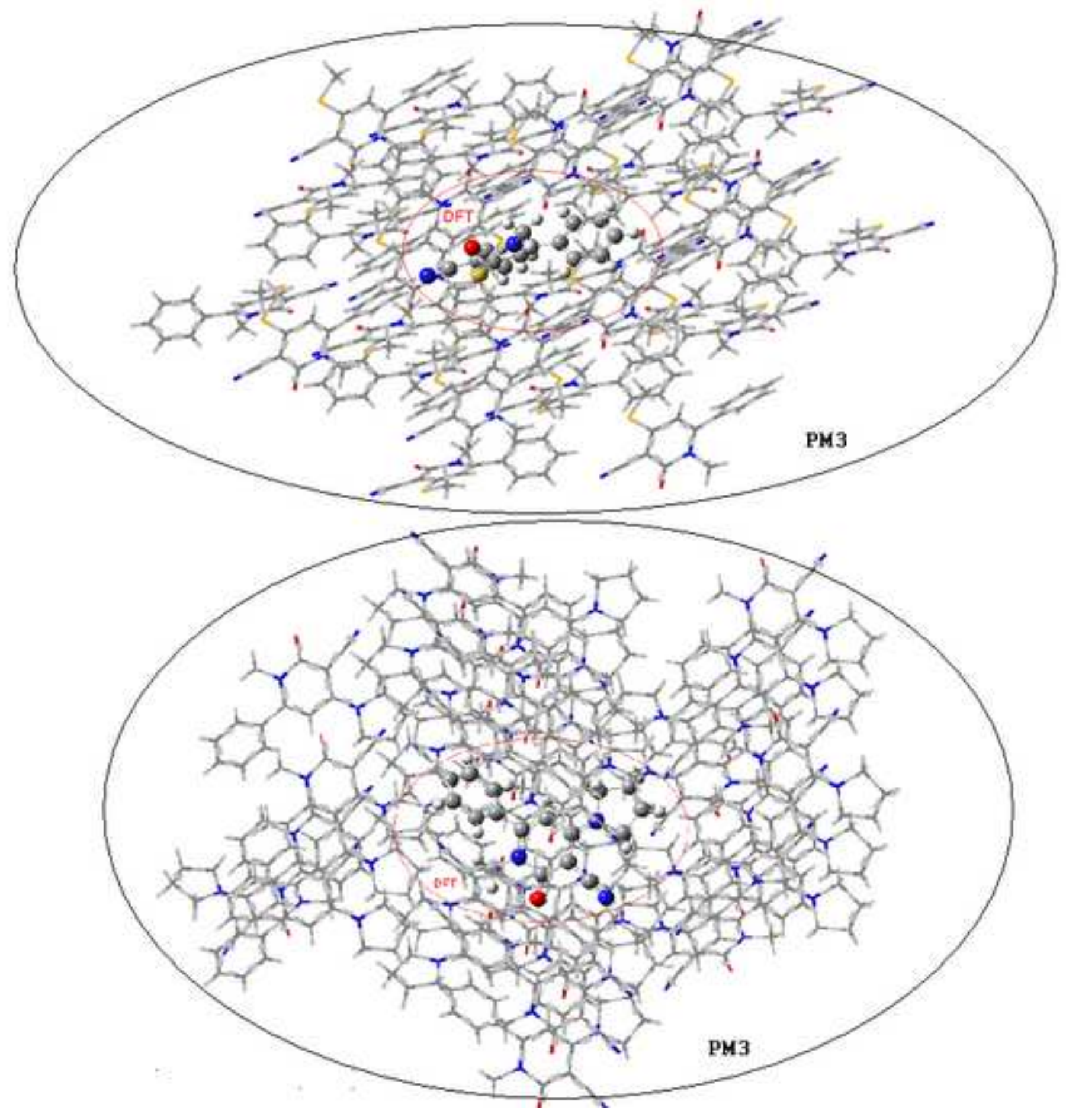


Fig. 3.

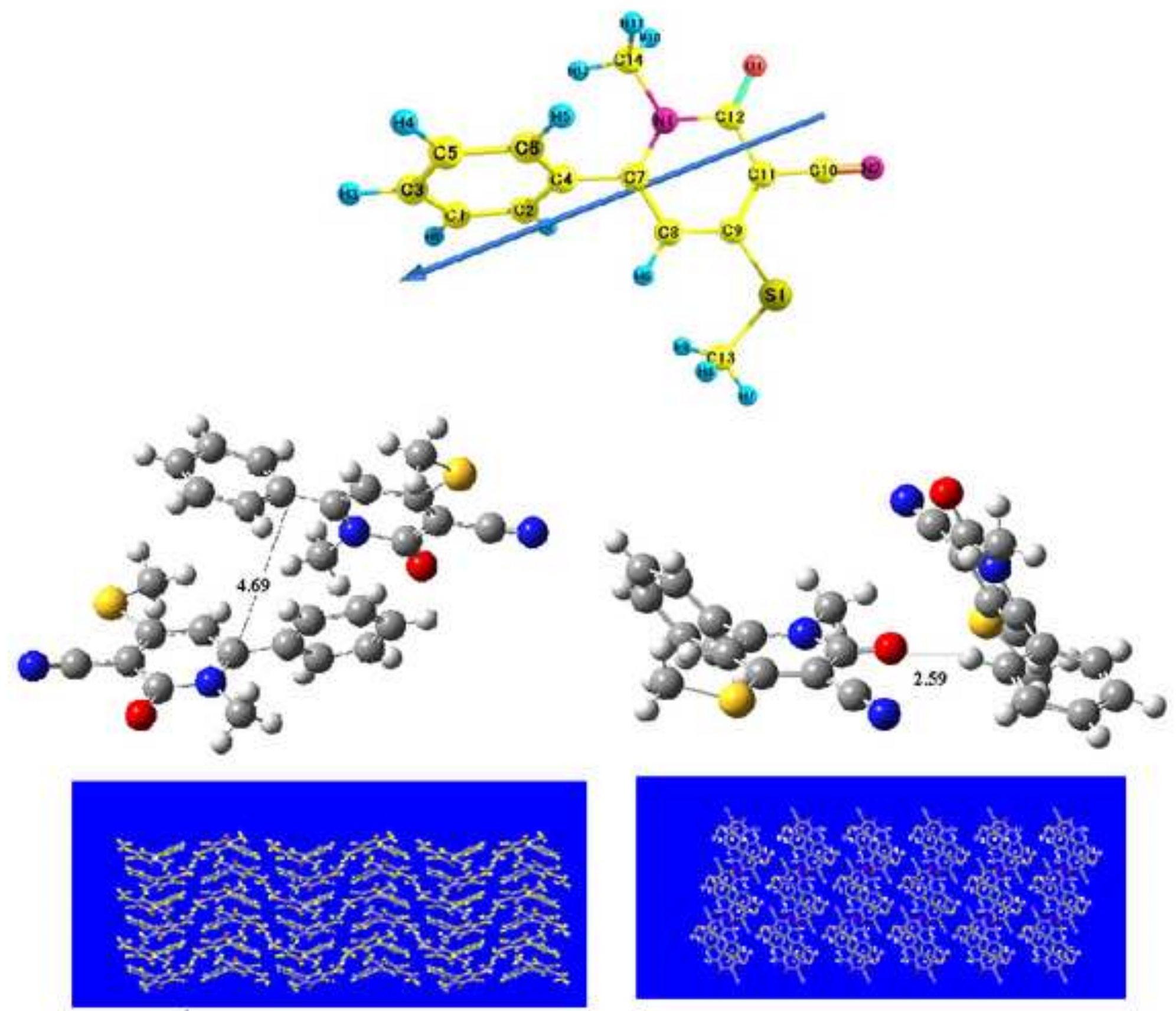


Fig. 4.

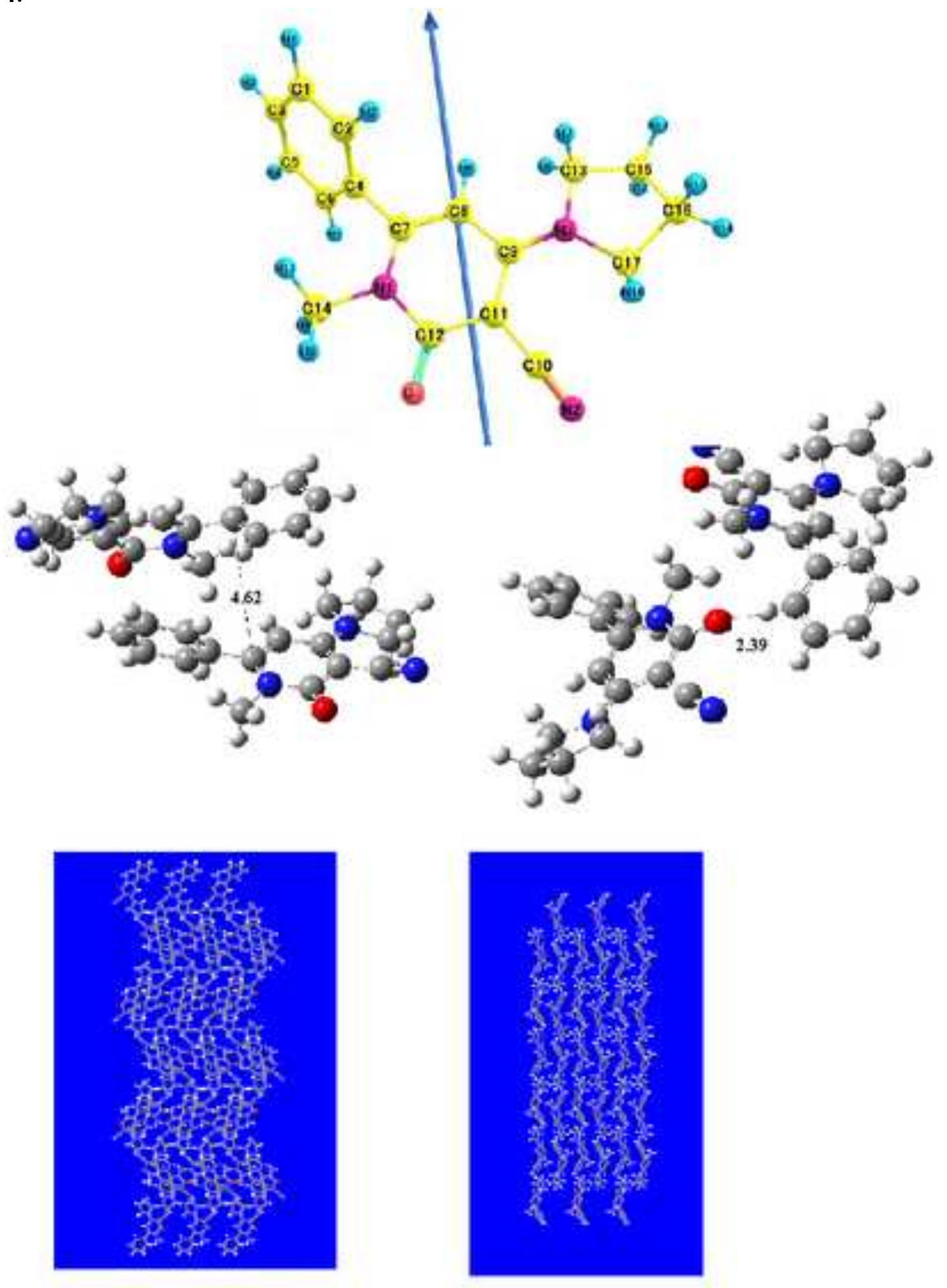


Fig. 5.
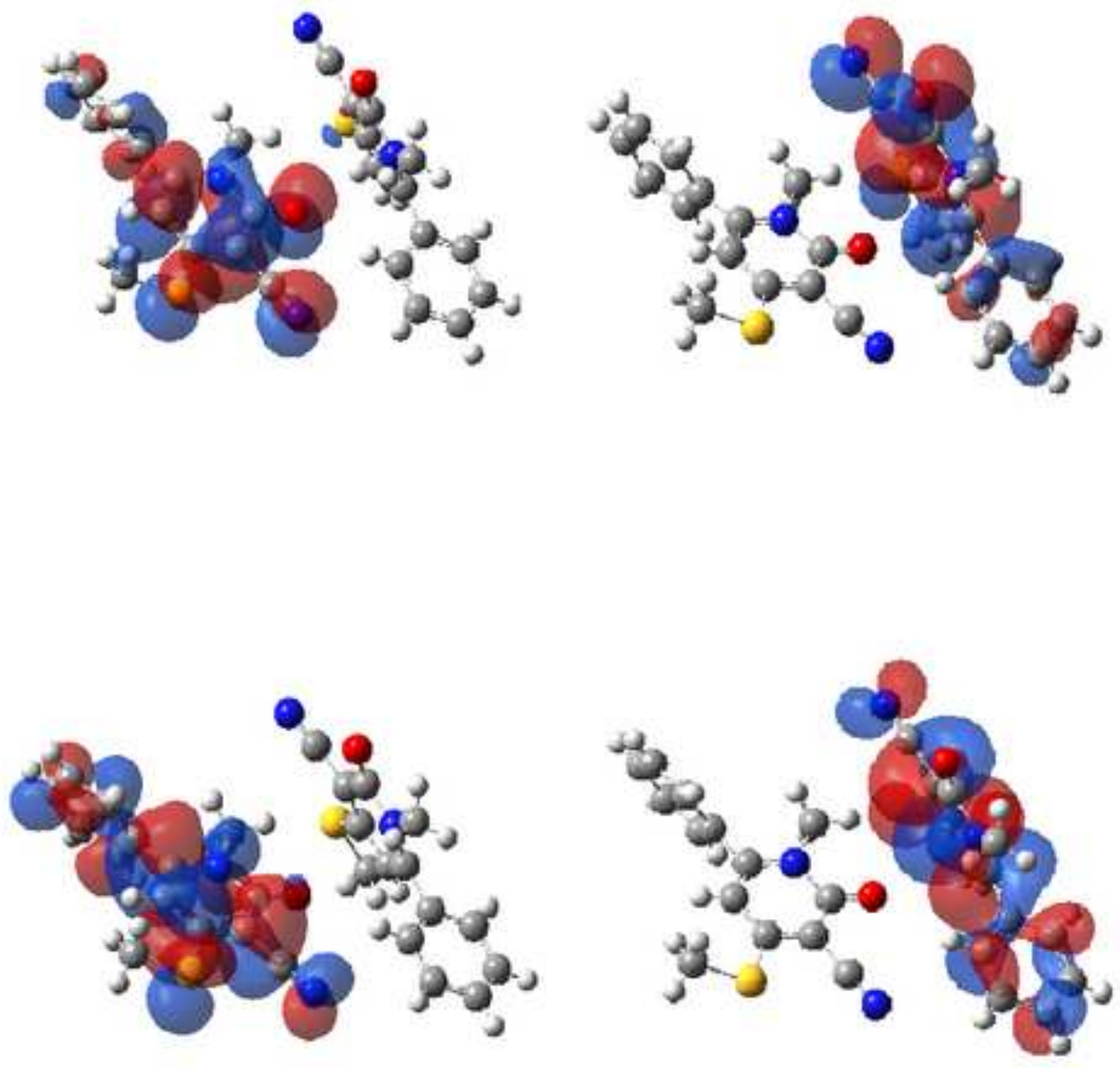
Fig. 6.

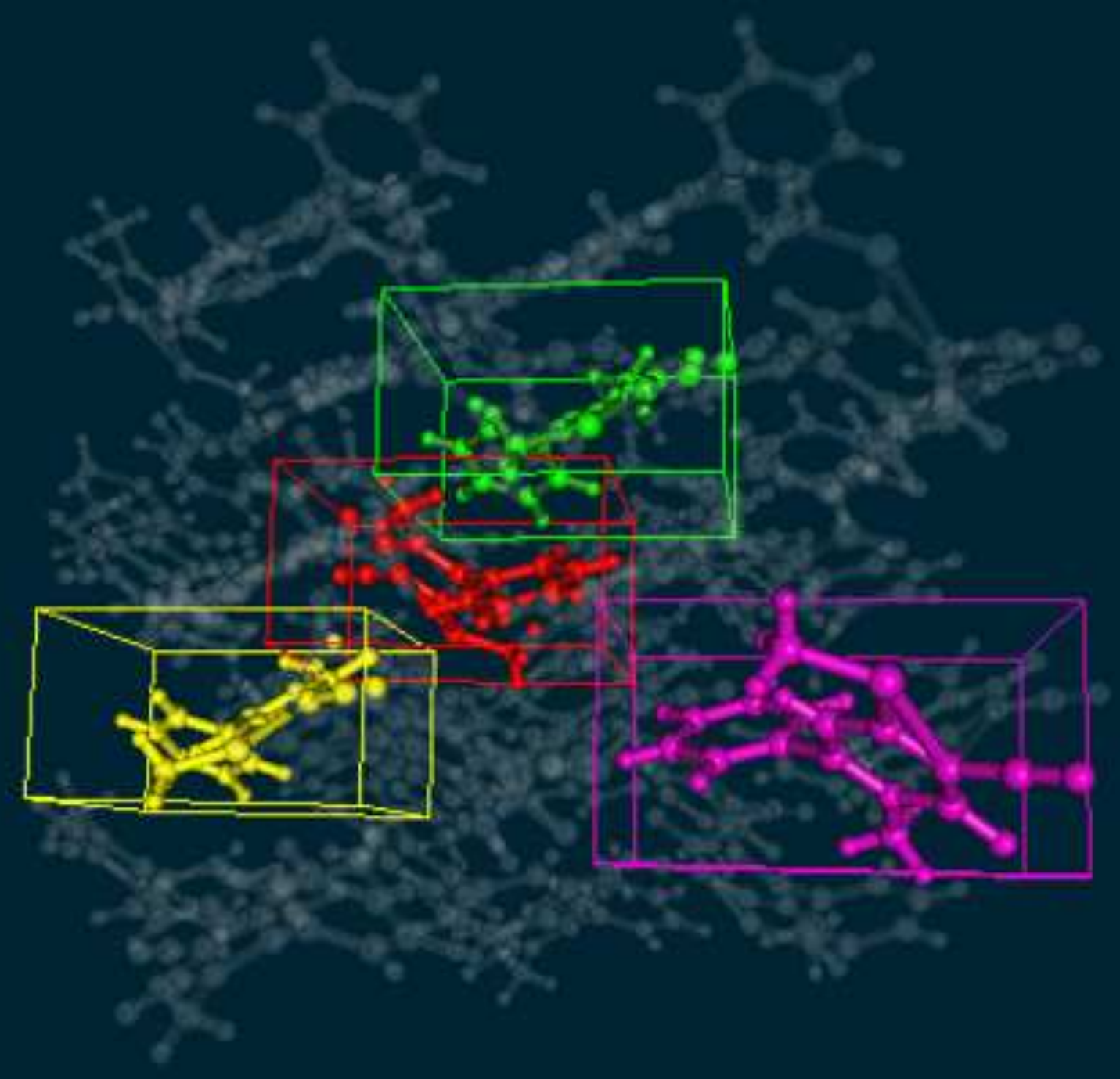


Fig. 7.

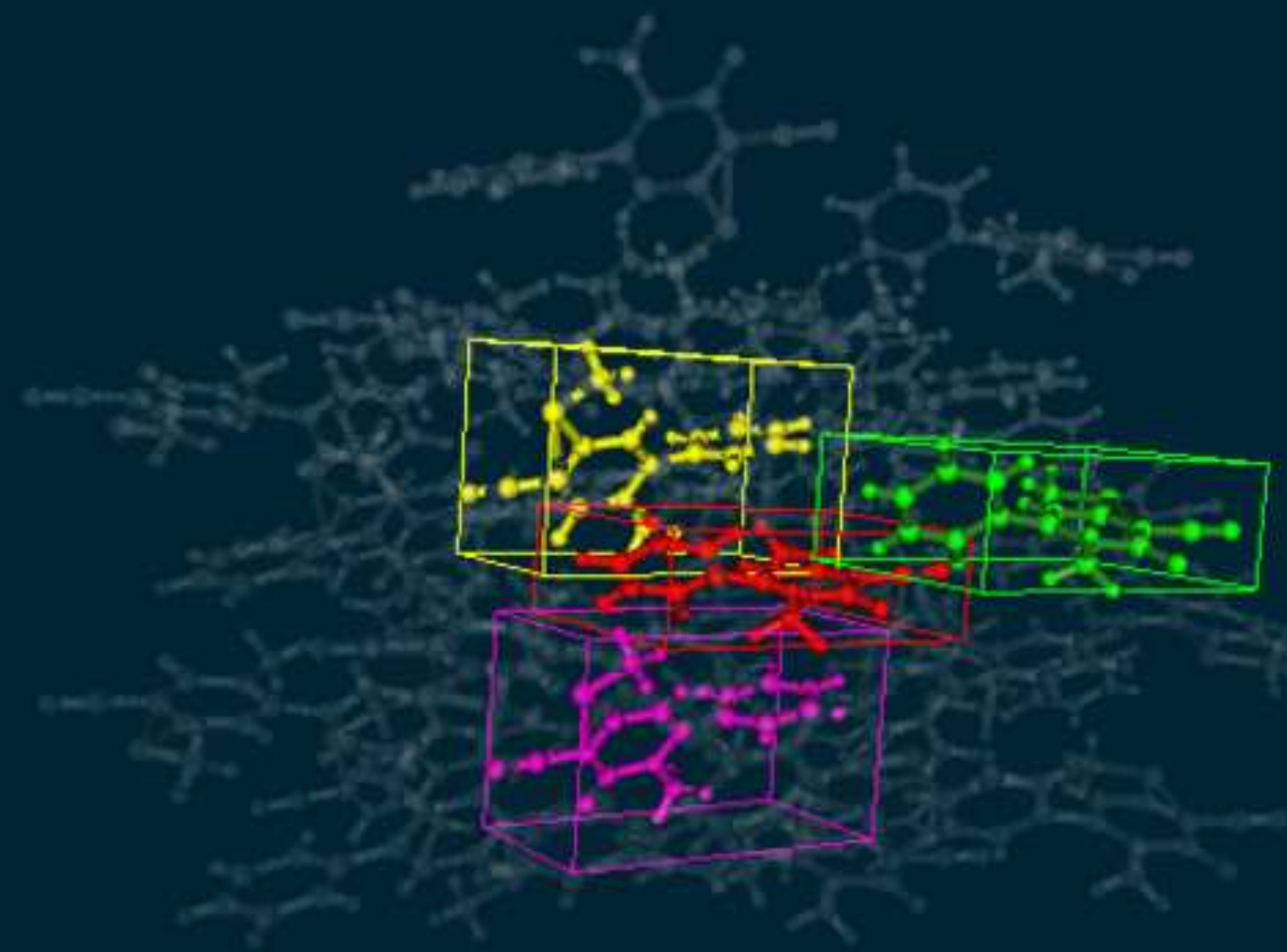


Table $1 \mathrm{UV} /$ vis and fluorescence maxima of $\mathbf{3}$ and $\mathbf{5}$

\begin{tabular}{|c|c|c|c|c|c|c|c|c|c|c|c|}
\hline \multirow[b]{2}{*}{ No. } & \multirow[b]{2}{*}{ position 4} & \multirow[b]{2}{*}{ position 6} & \multirow{2}{*}{$\begin{array}{c}\mathrm{UV} \lambda \max (\log \varepsilon) \\
\mathrm{nm}(\mathrm{EtOH})\end{array}$} & \multicolumn{4}{|c|}{ Fluorescence (EtOH) } & \multicolumn{4}{|c|}{ Fluorescence (solid) } \\
\hline & & & & $\operatorname{Ex} \max (\mathrm{nm})$ & Em max(nm) & $\mathrm{SS}^{\mathrm{a}}$ & $\phi$ & $\operatorname{Ex} \max (\mathrm{nm})$ & Em max(nm) & $\mathrm{SS}^{\mathrm{a}}$ & R.I. $^{\text {b }}$ \\
\hline 3a & SMe & $\mathrm{C}_{6} \mathrm{H}_{5}$ & $356(4.12)$ & & & & 0.00 & 346 & 513 & 167 & 0.99 \\
\hline $3 \mathbf{b}$ & $\mathrm{SMe}$ & $\mathrm{C}_{6} \mathrm{H}_{4}-\mathrm{OMe}(4)$ & $365^{c}$ & & & & 0.00 & 338 & 496 & 158 & 1.28 \\
\hline 3c & $\mathrm{SMe}$ & $\mathrm{C}_{6} \mathrm{H}_{3}-(\mathrm{OMe})_{2}(3,4)$ & $370^{c}$ & & & & 0.00 & 331 & 506 & 175 & 0.92 \\
\hline 3d & $\mathrm{SMe}$ & $\mathrm{C}_{6} \mathrm{H}_{3}-(\mathrm{OMe})_{2}(2,5)$ & $360(4.12)$ & & & & 0.00 & 347 & 476 & 129 & 1.22 \\
\hline $3 \mathbf{e}$ & $\mathrm{SMe}$ & $\mathrm{C}_{6} \mathrm{H}_{2}-(\mathrm{OMe})_{3}(3,4,5)$ & 364 (4.29) & & & & 0.00 & 345 & 518 & 173 & 0.62 \\
\hline $3 f$ & SMe & $\mathrm{C}_{6} \mathrm{H}_{4}-\mathrm{NMe}_{2}(4)$ & $410(4.67)$ & 417 & 508 & 91 & 0.03 & 340 & 558 & 218 & 1.24 \\
\hline $3 g$ & $\mathrm{SMe}$ & biphenyl & $364^{c}$ & & & & 0.00 & 336 & 492 & 156 & 0.21 \\
\hline $3 \mathbf{h}$ & $\mathrm{SMe}$ & 2-pyridyl & 366 (3.61) & & & & 0.00 & 350 & 502 & 152 & 0.14 \\
\hline $3 \mathbf{i}$ & $\mathrm{SMe}$ & 2-thienyl & $375^{c}$ & & & & 0.00 & 339 & 510 & 171 & 0.63 \\
\hline $3 \mathbf{j}$ & SMe & 2-furyl & 377 (4.39) & & & & 0.00 & 352 & 518 & 166 & 0.33 \\
\hline $3 \mathbf{k}$ & SMe & 6-styryl & $504^{\mathrm{c}}$ & & & & 0.00 & 335 & 560 & 225 & 0.23 \\
\hline $3 \mathbf{l}$ & $\mathrm{SMe}$ & 2-(4-dimethylaminophenyl)vinyl & $449(4.12)$ & & & & 0.00 & 327 & 564 & 237 & 0.04 \\
\hline $5 a$ & pyrrolidino & $\mathrm{C}_{6} \mathrm{H}_{5}$ & 317 (3.85) & & & & 0.00 & 350 & 453 & 103 & 0.42 \\
\hline $5 \mathbf{b}$ & pyrrolidino & $\mathrm{C}_{6} \mathrm{H}_{4}-\mathrm{OMe}(4)$ & $324(4.48)$ & & & & 0.00 & 350 & 452 & 102 & 3.84 \\
\hline $5 c$ & pyrrolidino & $\mathrm{C}_{6} \mathrm{H}_{3}-(\mathrm{OMe})_{2}(3,4)$ & 386 (3.95) & & & & 0.00 & 344 & 497 & 153 & 0.71 \\
\hline $5 d$ & pyrrolidino & 2-pyridyl & 335 (4.15) & & & & 0.00 & 346 & 457 & 111 & 0.56 \\
\hline $5 e$ & pyrrolidino & 2-furyl & $335(4.21)$ & & & & 0.00 & 349 & 478 & 129 & 0.05 \\
\hline
\end{tabular}

a Stoke's Shift $=$ Em max(nm) - Ex max(nm).

b Relative intensity of fluorescence in solid state, using Abqas a standard.

${ }^{\mathrm{c}}$ insufficient solubility. 
Table 2 UV/vis and fluorescence maxima of $\mathbf{6}$ and 7

\begin{tabular}{|c|c|c|c|c|c|c|c|c|c|c|c|}
\hline \multirow[b]{2}{*}{ No. } & \multirow[b]{2}{*}{ position 4} & \multirow[b]{2}{*}{ position 6} & \multirow{2}{*}{$\begin{array}{c}\mathrm{UV} \lambda \max (\log \varepsilon) \\
\mathrm{nm}(\mathrm{EtOH})\end{array}$} & \multicolumn{4}{|c|}{ Fluorescence $(\mathrm{EtOH})$} & \multicolumn{4}{|c|}{ Fluorescence (solid) } \\
\hline & & & & $\operatorname{Ex} \max (\mathrm{nm})$ & $E m \max (n m)$ & $\mathrm{SS}^{\mathrm{a}}$ & $\phi$ & Ex max(nm) & Em max(nm) & $\mathrm{SS}^{\mathrm{a}}$ & R.I. $^{b}$ \\
\hline $6 a$ & SMe & $\mathrm{C}_{6} \mathrm{H}_{5}$ & $310(4.33)$ & 268 & 623 & 355 & $0.01>$ & 356 & 438 & 82 & 1.34 \\
\hline $6 b$ & SMe & $\mathrm{C}_{6} \mathrm{H}_{4}-\mathrm{OMe}(4)$ & $336(4.62)$ & & & & 0.00 & 350 & 452 & 102 & 1.83 \\
\hline $6 c$ & SMe & $\mathrm{C}_{6} \mathrm{H}_{3}-(\mathrm{OMe})_{2}(3,4)$ & $344(4.43)$ & 246 & 430 & 184 & $0.01>$ & 352 & 441 & 89 & 1.12 \\
\hline 6d & $\mathrm{SMe}$ & $\mathrm{C}_{6} \mathrm{H}_{3}-(\mathrm{OMe})_{2}(2,5)$ & $350(4.08)$ & 231 & 460 & 229 & $0.01>$ & 343 & 442 & 99 & 0.18 \\
\hline $6 e$ & $\mathrm{SMe}$ & $\mathrm{C}_{6} \mathrm{H}_{2}-(\mathrm{OMe})_{3}(3,4,5)$ & 333 (4.18) & 334 & 450 & 116 & $0.01>$ & 341 & 473 & 132 & 0.91 \\
\hline $6 f$ & $\mathrm{SMe}$ & $\mathrm{C}_{6} \mathrm{H}_{4}-\mathrm{NMe}_{2}(4)$ & $383(4.72)$ & 386 & 488 & 102 & 0.01 & 341 & 488 & 147 & 1.13 \\
\hline $6 g$ & SMe & biphenyl & 333 (4.59) & 336 & 426 & 90 & 0.01 & 353 & 449 & 96 & 0.19 \\
\hline $6 h$ & SMe & 2-pyridyl & $313(4.34)$ & & & & 0.00 & 344 & 447 & 103 & 0.10 \\
\hline $6 \mathbf{j}$ & SMe & 2-furyl & $343(4.30)$ & 344 & 426 & 82 & $0.01>$ & 344 & 495 & 151 & 1.61 \\
\hline 61 & SMe & 2-(4-dimethylaminophenyl)vinyl & $450(4.25)$ & & & & 0.00 & 300 & 488 & 188 & 0.02 \\
\hline $7 a$ & SMe & $\mathrm{C}_{6} \mathrm{H}_{5}$ & $350(4.15)$ & & & & 0.00 & 334 & 492 & 158 & 0.94 \\
\hline $7 \mathbf{b}$ & SMe & $\mathrm{C}_{6} \mathrm{H}_{4}-\mathrm{OMe}(4)$ & $350(4.77)$ & & & & 0.00 & 355 & 443 & 88 & 3.90 \\
\hline 7c & SMe & $\mathrm{C}_{6} \mathrm{H}_{3}-(\mathrm{OMe})_{2}(3,4)$ & $350(4.08)$ & & & & 0.00 & 344 & 434 & 90 & 1.62 \\
\hline 7d & SMe & $\mathrm{C}_{6} \mathrm{H}_{3}-(\mathrm{OMe})_{2}(2,5)$ & $350(4.06)$ & & & & 0.00 & 346 & 431 & 85 & 0.18 \\
\hline $7 e$ & SMe & $\mathrm{C}_{6} \mathrm{H}_{2}-(\mathrm{OMe})_{3}(3,4,5)$ & 350 (4.09) & & & & 0.00 & 349 & 456 & 107 & 0.85 \\
\hline $7 f$ & SMe & $\mathrm{C}_{6} \mathrm{H}_{4}-\mathrm{NMe}_{2}(4)$ & 388 (4.63) & 257 & 454 & 197 & $0.01>$ & 340 & 533 & 193 & 1.08 \\
\hline $7 \mathbf{j}$ & SMe & 2-furyl & $374(5.14)$ & & & & 0.00 & 340 & 488 & 148 & 2.01 \\
\hline $7 \mathbf{k}$ & $\mathrm{SMe}$ & 6-styryl & 375 (4.59) & & & & 0.00 & 352 & 518 & 166 & 1.65 \\
\hline
\end{tabular}

${ }^{\text {a }}$ Stoke's Shift = Em max(nm) - Ex max(nm).

b Relative intensity of fluorescence in solid state, using Abqas a standard.

c insufficient solubility. 
Table 3 UV/vis and fluorescence maxima of 8

\begin{tabular}{|c|c|c|c|c|c|c|c|c|c|c|c|}
\hline \multirow[b]{2}{*}{ No. } & \multirow[b]{2}{*}{ position 4} & \multirow[b]{2}{*}{ position 6} & \multirow{2}{*}{$\begin{array}{c}\text { UV } \lambda \max (\log \varepsilon) \\
n m(E t O H)\end{array}$} & \multicolumn{4}{|c|}{ Fluorescence (EtOH) } & \multicolumn{4}{|c|}{ Fluorescence (solid) } \\
\hline & & & & $\operatorname{Ex} \max (\mathrm{nm})$ & Em max(nm) & $\mathrm{SS}^{\mathrm{a}}$ & $\phi$ & $\operatorname{Ex} \max (\mathrm{nm})$ & Em max(nm) & $\mathrm{SS}^{\mathrm{a}}$ & R.I. $^{\text {b }}$ \\
\hline $8 \mathbf{a}$ & pyrrolidino & $\mathrm{C}_{6} \mathrm{H}_{5}$ & $310(4.08)$ & & & & 0.00 & 394 & 448 & 54 & 0.44 \\
\hline $8 \mathbf{b}$ & pyrrolidino & $\mathrm{C}_{6} \mathrm{H}_{4}-\mathrm{OMe}(4)$ & $311(4.16)$ & & & & 0.00 & 391 & 440 & 49 & 0.20 \\
\hline $8 c$ & pyrrolidino & $\mathrm{C}_{6} \mathrm{H}_{3}-(\mathrm{OMe})_{2}(3,4)$ & $310(4.17)$ & & & & 0.00 & 357 & 444 & 87 & 1.42 \\
\hline 8d & pyrrolidino & $\mathrm{C}_{6} \mathrm{H}_{3}-(\mathrm{OMe})_{2}(2,5)$ & $315(4.14)$ & & & & 0.00 & 348 & 440 & 92 & 0.01 \\
\hline $8 e$ & pyrrolidino & $\mathrm{C}_{6} \mathrm{H}_{2}-(\mathrm{OMe})_{3}(3,4,5)$ & $343(3.84)$ & & & & 0.00 & 345 & 459 & 104 & 5.93 \\
\hline
\end{tabular}

${ }^{\text {a }}$ Stoke's Shift $=$ Em max(nm) - Ex max(nm).

b Relative intensity of fluorescence in solid state, using Abqas a standard.

c insufficient solubility. 
Table 4.

Computed UV-vis $\lambda \max (\mathrm{nm})$ and oscillator strengths of $3,5,6$.

\begin{tabular}{lll} 
& B3LYP & PBE0 \\
\hline 3a & $339 / 0.48$ & $332 / 0.50$ \\
3b & $355 / 0.73$ & $347 / 0.74$ \\
3c & $358 / 0.69$ & $348 / 0.72$ \\
3d & $398 / 0.10$ & $379 / 0.13$ \\
3e & $351 / 0.50$ & $341 / 0.56$ \\
3f & $412 / 0.87$ & $400 / 0.92$ \\
$3 \mathrm{~g}$ & $363 / 0.96$ & $352 / 0.98$ \\
3h & $360 / 0.95$ & $351 / 0.96$ \\
3i & $361 / 0.60$ & $353 / 0.61$ \\
3j & $368 / 0.67$ & $360 / 0.69$ \\
3k & $397 / 1.10$ & $387 / 1.13$ \\
3l & $480 / 1.40$ & $467 / 1.46$ \\
5a & $319 / 0.31$ & $310 / 0.34$ \\
5b & $325 / 0.64$ & $317 / 0.66$ \\
5c & $335 / 0.61$ & $325 / 0.65$ \\
5d & $352 / 0.21$ & $340 / 0.25$ \\
5e & $346 / 0.52$ & $337 / 0.58$ \\
$6 \mathrm{a}$ & $317 / 0.34$ & $308 / 0.41$ \\
$6 \mathrm{~b}$ & $339 / 0.82$ & $329 / 0.86$ \\
$6 \mathrm{c}$ & $324 / 0.61$ & $315 / 0.66$ \\
$6 \mathrm{~d}$ & $383 / 0.07$ & $365 / 0.08$ \\
$6 \mathrm{e}$ & $316 / 0.39$ & $307 / 0.50$ \\
$6 \mathrm{f}$ & $373 / 0.77$ & $361 / 0.82$ \\
$6 \mathrm{~g}$ & $330 / 0.73$ & $320 / 0.79$ \\
$6 \mathrm{~h}$ & $329 / 0.05$ & $317 / 0.07$ \\
$6 \mathrm{j}$ & $320 / 0.51$ & $312 / 0.58$ \\
$6 \mathrm{l}$ & $404 / 1.19$ & $392 / 1.25$
\end{tabular}


Table 5.

Computed UV-vis first intense $\lambda \max (\mathrm{nm})$ of $7 \mathrm{a}$ and $8 \mathrm{a}$.

$\mathrm{TD}(B 3 L Y P) / 6-31 G(d)$

TD(B3LYP)/6-31G(d,p)

$T D(B 3 L Y P) / 6-31+G(d, p)$

$\mathrm{TD}(\mathrm{PBE} 0) / 6-31 \mathrm{G}(\mathrm{d})$

$\mathrm{TD}(\mathrm{PBE} 0) / 6-31+\mathrm{G}(\mathrm{d}, \mathrm{p})$

$7 a$

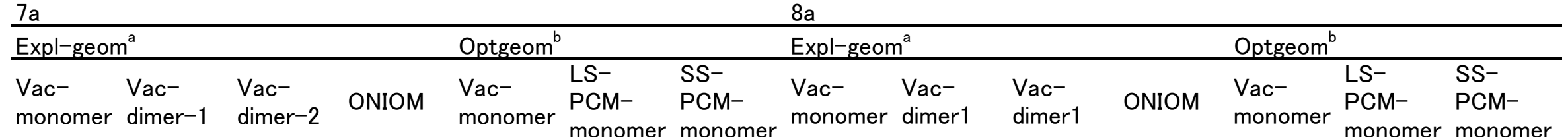

monomer dimer-1 dimer-2 ONIOM monomer ${ }_{\text {mon- }} \mathrm{PCM}^{-}$monomer dimer1 dimer1

TD(CAM-B3LYP)/6-31G(d)

$\begin{array}{ll}331 & 340 \\ 331 & 341 \\ 333 & 342 \\ 323 & 327 \\ 325 & 328 \\ 305 & 308 \\ 307 & 309\end{array}$

$\begin{array}{ll}340 & 371 \\ 341 & 371 \\ 342 & 370 \\ 327 & 345 \\ 328 & 345 \\ 308 & 308 \\ 309 & 309\end{array}$

$\begin{array}{ll}371 & 33 \\ 371 & 331 \\ 370 & 333 \\ 345 & 323 \\ 345 & 325 \\ 308 & 305 \\ 309 & 307\end{array}$

331
331
333
323
325
305
307

337
337
339
329
331
311
312

$329 \quad 337$

337
337

331

340

345
345

331

nomer

$\begin{array}{ll}\mathrm{PCM}- & \mathrm{PCM}- \\ \text { monomer monomer }\end{array}$

$\mathrm{TD}(\mathrm{CAM}-\mathrm{B} 3 \mathrm{LYP}) / 6-31+\mathrm{G}(\mathrm{d}, \mathrm{p})$

a Geometries extracted from crystallorganic data.

b Optimized geometries with DFT(B3LYP)/6-311G(2d,2p). 
Table 6.

Computed UV-vis and emission $\lambda \max (\mathrm{nm})$ and oscillator strengths of $7 \mathrm{a}$ and $8 \mathrm{a}$ using CASSCF and MS-CASPT2.

\begin{tabular}{|c|c|c|c|c|}
\hline \multirow{4}{*}{$\begin{array}{l}\text { Vac-CAS } \\
\text { LR-PCM-CAS }\end{array}$} & \multicolumn{2}{|l|}{$7 a$} & \multicolumn{2}{|l|}{$8 a$} \\
\hline & $\overline{U V-v i s^{a}}$ & Fluorescence ${ }^{b}$ & $U V-v^{2}{ }^{a}$ & Fluorescence $^{\mathrm{b}}$ \\
\hline & 302 & 361 & 274 & 332 \\
\hline & 251 & 344 & 255 & 304 \\
\hline Vac-PT ${ }^{d}$ & $332 / 0.21$ & $418 / 0.31$ & $311 / 0.14$ & $397 / 0.37$ \\
\hline LR-PCM-PT2 & $294 / 0.27$ & $390 / 0.45$ & $296 / 0.15$ & $365 / 0.29$ \\
\hline
\end{tabular}

a Geometries optimized DFT(B3LYP)/6-3111G(2d,2p).

b Geometries optimized TDDFT(B3LYP)/6-31 + G(d).

c 4-state-averaged CASSCF $(10,10) /$ ANO-L.

d 4-state-averaged MS-CASPT2(10,10)/ANO-L. 
Table 7.

Key geometrical parameters of $7 a$ and $8 \mathrm{a}$ in $\mathrm{S}_{0}$ and $\mathrm{S}_{1}$ state.

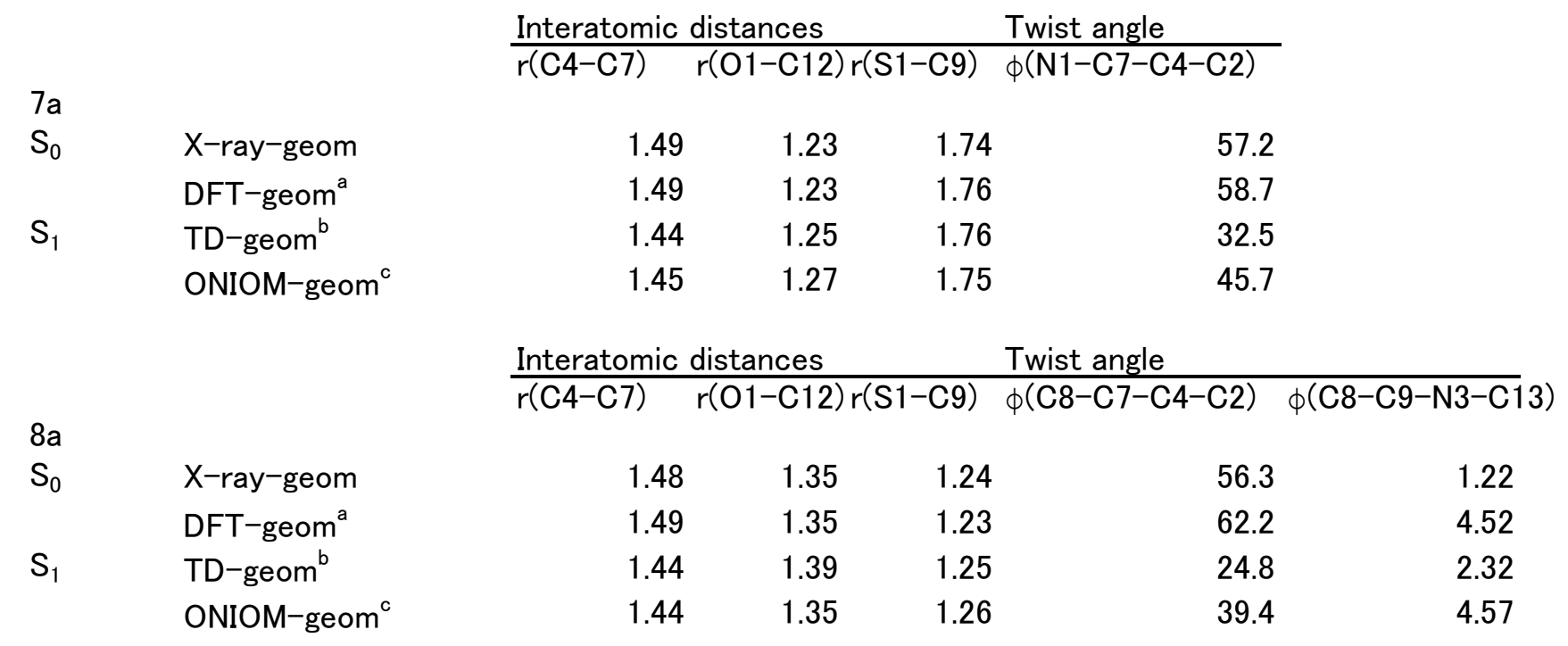

a Optimized geometries with DFT(B3LYP)/6-311G(2d,2p).

b Optimized geometries with TDDFT(B3LYP)/6-31 + G(d).

c Optimized geometries with ONIOM(TD(B3LYP)/6-31 + G(d):PM3). 
Table 8.

FMO-TDDFT $\lambda$ max of $7 a$ and $8 a$ in $S_{0}$ and $S_{1}$ state.

\begin{tabular}{lrrrrrrr}
$7 \mathrm{la}$ & $8 \mathrm{a}$ & & \\
\hline UV-vis & & Fluorescence & \multicolumn{1}{l}{ UV-vis } & & \multicolumn{3}{l}{ Fluorescence } \\
\hline FMO-1 & FMO-2 & FMO-1 & FMO-2 & FMO-1 & FMO-2 & FMO-1 & FMO-2 \\
320 & 326 & 403 & 415 & 308 & 314 & 392 & 397
\end{tabular}


Table 9.

Computed fluorescence $\lambda \max (\mathrm{nm})$ of $3 \mathrm{f}$.

TD-genom $^{\mathrm{a}}$

\begin{tabular}{|c|c|c|c|}
\hline \multicolumn{2}{|c|}{ R3I YP $\quad$ In vacuo } & \multicolumn{2}{|c|}{ LR-PCM SS-PCM } \\
\hline B3LYP & 436 & 437 & 470 \\
\hline PBE0 & 424 & 428 & 459 \\
\hline CAM-B3LYP & 406 & 398 & 434 \\
\hline CAS-genom ${ }^{b}$ & \multirow{2}{*}{\multicolumn{3}{|c|}{ PT2 }} \\
\hline CAS & & & \\
\hline & LR-PCM & vac & CM \\
\hline 391 & 346 & 411 & 359 \\
\hline
\end{tabular}

a An optimized geometry with TDDFT(B3LYP)/6-31 + G(d).

b An optimized geometry with CASSCF $(10 \mathrm{e}, 10 \mathrm{o}) / \mathrm{ANO}-\mathrm{L}$ 
Table 10.

Computed fluorescence $\lambda \max (\mathrm{nm})$ and oscillator strengths of $7 \mathrm{a}$ and $8 \mathrm{a}$.

$\mathrm{TD}(\mathrm{B} 3 \mathrm{LYP}) / 6-31 \mathrm{G}(\mathrm{d})$

$\mathrm{TD}(\mathrm{B} 3 \mathrm{LYP}) / 6-31+\mathrm{G}(\mathrm{d}, \mathrm{p})$

$\mathrm{TD}(\mathrm{PBE} 0) / 6-31 \mathrm{G}(\mathrm{d})$

$\mathrm{TD}(\mathrm{PBE} 0) / 6-31+\mathrm{G}(\mathrm{d}, \mathrm{p})$

TD(CAM-B3LYP) $/ 6-31 \mathrm{G}(\mathrm{d})$

$\mathrm{TD}(\mathrm{CAM}-\mathrm{B} 3 \mathrm{LYP}) / 6-31+\mathrm{G}(\mathrm{d}, \mathrm{p})$

$7 a$

$8 a$

\begin{tabular}{llll}
$7 \mathrm{a}$ & \multicolumn{3}{l}{$8 \mathrm{a}$} \\
\hline TD-geom $^{\mathrm{a}}$ & ONIOM-geom $^{\mathrm{b}}$ & TD-geom $^{\mathrm{a}}$ & ONIOM-geom $^{\mathrm{b}}$ \\
$446 / 0.20$ & $421 / 0.18$ & $463 / 0.15$ & $435 / 0.14$ \\
$448 / 0.22$ & $435 / 0.20$ & $466 / 0.16$ & $436 / 0.15$ \\
$432 / 0.23$ & $421 / 0.22$ & $445 / 0.17$ & $418 / 0.16$ \\
$434 / 0.25$ & $421 / 0.22$ & $447 / 0.18$ & $419 / 0.17$ \\
$398 / 0.31$ & $387 / 0.27$ & $395 / 0.26$ & $371 / 0.24$ \\
$400 / 0.33$ & $387 / 0.29$ & $397 / 0.27$ & $371 / 0.25$
\end{tabular}

a $T D(B 3 L Y P) / 6-31+G(d)$.

b ONIOM(TD(B3LYP)/6-31 + G(d):PM3). 